\title{
Comentarios
}

\section{Tres años de gobierno de Armando Calderón Sol}

Como ya es rutina, el 1 de junio el Presidente de la República, Armando Calderón Sol, dirigió un mensaje a la nación con motivo del cumplimiento de sus tres años de gobierno. Entre los puntos medulares de su alocución al pleno legislativo, Calderón Sol destacó la necesidad de elaborar un proyecto nacional de largo plazo, "para dar estabilidad y continuidad al país, más allá de los períodos de Gobierno, a fin de convertir a nuestro país en un lugar atractivo para la inversión y generación de empleo, que eleven el bienestar y calidad de vida de la población". Precisamente, en respuesta a esa necesidad, "tomamos la decisión de crear una Comisión para que proponga el mecanismo que permita la formulación del Plan de Desarrollo Nacional, para lo cual convocamos a distinguidas personalidades, de reconocida capacidad y distintos pensamientos políticos".

No podían faltar en la evaluación presidencial las temáticas económica, social y de seguridad ciudadana. Sobre el primer ámbito, el Presidente de la República volvió sobre el debatido tema de la desaceleración, insistiendo en su carácter "temporal", "pero ya se está experimentando una recuperación, y para asegurar su sostenibilidad, es necesario volvernos más competitivos". Tampoco no olvidó repetir el estribillo de sus asesores económicos, según los cuales "la inflación bajo el siete por ciento, siendo la tasa más baja de los últimos veinte años y la más baja de Centroamérica, lo que ha facilitado el descenso significativo de las tasas de interes; el tipo de cambio se mantiene estable y, como resultado de la fortaleza del sector externo, al mes de abril de este año, las exportaciones crecieron en un treinta y tres por ciento, en relación con el mismo período del año anterior".
Pese a que todo el mundo sabe el desinterés mostrado por el gobierno en el desarrollo agropecuario -empeñado como ha estado en propiciar la terciarización de la economía- Calderón Sol habló, sin sonrojarse siquiera, de una "reactivación" del agro. "Es importante mencionar —dijo- que la reactivación del agro está ya en marcha, gracias a una serie de medidas que hemos adoptado para apoyar a uno de los sectores que más sufrió durante los años del conflicto. Nos satisface señalar que este año la zafra alcanzó un récord histórico en la producción azucarera del país y estamos proyectando, para el próximo año agrícola, lograr otros altos niveles de producción agropecuaria. Esto nos compromete a redoblar nuestra atención hacia ese importante sector de la economía nacional".

En el plano social, se refirió a la importancia que su gestión ha dado a la "inversión en capital humano", especialmente en la asignación de recursos públicos a la educación, la salud, la vivienda y el desarrollo urbano. "Uno de nuestros principales compromisos ha sido la inversión en el capital humano, mediante el desarrollo de programas sociales que efectivamente beneficien a los sectores más necesitados de la población. En cumplimiento de ello hemos hecho grandes transformaciones en la asignación de los recursos públicos, incrementando las partidas presupuestarias para el área social en un setenta y cinco por ciento en los últimos tres años, y actualmente representa el treinta y cuatro por ciento del presupuesto general de la nación".

(a) Educación. "Convencidos de que la educación es la piedra angular para superar la pobreza y 
generar movilidad social, hemos incrementado los esfuerzos y recursos del Gobierno, para impulsar la Reforma Educativa y financiar innovadores programas de educación y atención a los sectores más necesitados, con los programas Escuela Saludable y EDUCO, al que se le ha otorgado un premio internacional por constituir un proyecto modelo en el ámbito mundial".

(b) Salud. "La salud es otro componente básico de nuestro plan de desarrollo social, por lo que hemos continuado desarrollando el proceso de modernización de la gestión del Ministerio de Salud Pública y Asistencia Social, así como del Instituto Salvadoreño del Seguro Social, registrando significativos logros en el mejoramiento de la calidad y cobertura de los servicios asistenciales, con un impacto beneficioso para la salud del pueblo. Otros componentes de la salud son el agua potable y el saneamiento ambiental, por lo cual ANDA ha incrementado la cobertura de sus servicios a más de un millón de habitantes y seguiremos trabajando hasta llevarla a todas las comunidades que la necesiten".

(c) Vivienda y desarrollo urbano. "La vivienda y el desarrollo urbano, ocupan también la atención especial del Gobierno. En este período, a través de FONAVIPO y el Fondo Social para la Vivienda, se otorgaron entre donativos y préstamos más de ochocientos treinta y cuatro millones de colones, favoreciendo a más de veinticinco mil familias. De esta manera estamos atendiendo las más grandes necesidades y aspiraciones de la familia, como es el tener una casa digna y segura".

Por último, el mandatario se refirió a la seguridad ciudadana, considerada por él como "una alta prioridad del gobierno". Por ser ello así, "le hemos dado un tratamiento especial, promoviendo iniciativas de ley para fortalecer el combate contra la delincuencia, coordinando acciones conjuntas con las demás instituciones del Gobierno; y asignando a la Seguridad Pública en este ejercicio, la cantidad de mil trescientos millones de colones, que es el doble de lo asignado en mil novecientos noventa y cuatro. La labor desplegada por la Academia Nacional de Seguridad Pública y la Policía Nacional Civil, bajo la coordinación del Ministerio de Seguridad Pública, ha sido ardua y cada vez más efectiva, desarticulando peligrosas bandas de criminales en distintos lugares del país. Aunque la institución policial ha tenido un despliegue notable y es satisfactorio su trabajo global, reconocemos que aún hace falta completar su personal para lograr toda la cobertura territorial, así como mejorar su eficiencia y conducta profesional".

Una vez más, el Presidente Calderón Sol pasó de largo sobre los graves problemas del país y sobre las contradicciones y desatinos de su equipo de gobierno. La debilidad de fondo de su planteamiento estriba en que se sostiene en una teoría del "rebalse" cuya validez ha sido refutada una y otra vez por los hechos. El Presidente -0 quienes le redactaron su discurso- piensan que con proclamar un "crecimiento económico", un "aumento de las exportaciones" o un "descenso en las tasas de interés" la situación de los sectores sociales menos favorecidos automáticamente va a $\longrightarrow$ o está en camino de- mejorar.

Más bien, sucede todo lo contrario: el control de la inflación y el crecimiento económico no se han traducido en algún beneficio para la mayor parte de la población, sino en una profundización de sus condiciones de pobreza. Una prueba de ello, aunque no la única, son los salarios mínimos vigentes en el país, que se han deteriorado en forma significativa y no alcanzan ni siquiera para cubrir -con su valor nominal de 1,150 colones- la canasta de alimentos, cuyo valor es de 2,150 colones. Ni qué decir de lo lejos que se encuentran los salarios mínimos de cubrir la canasta básica $-4,721.6$ colones.

Además, como se señala en el semanario Proceso, "el problema con los salarios mínimos es que éstos no son sólo insuficientes para cubrir el costo de la canasta básica, sino que también pierden constantemente poder adquisitivo. Esta caída es tan aguda que, desde 1979 , se estima que los salarios mínimos reales han caído en aproximadamente 63 por ciento; lo cual implica que el salario mínimo real actual sólo representa un 37 por ciento del vigente para 1979. Ello muy a pesar de que, en términos nominales, los salarios mínimos hayan pasado de 270 a 1,150 colones, para el caso de industria y comercio. El último incremento de los salarios mínimos nominales fue en junio de 1995 y, de acuerdo con algunas estimaciones, para ese año el promedio del salario mínimo real fue de 840.23 colones; en mayo pasado se estima que este valor habría caído por debajo de los 800 colones" ("Salario mínimo y necesidades básicas", Proceso, No. 762, pp. 6-7).

Que con esta precariedad en la que viven los trabajadores salvadoreños -sin mencionar a los que 
están desempleados o subempleados-, el Presidente haga alarde de la preocupación de su gobierno por el bienestar social es un franco desatino. Ha habido un indudable crecimiento económico, pero del mismo se han beneficiado, casi exclusivamente, los grupos empresariales que manejan las principales industrias y las actividades financieras y bancarias. Por su parte, el sector agrícola no se ha beneficiado de ese crecimiento, sino que, por el contrario, atraviesa por una severa crisis que hace necesario que el gobierno "redoble" seriamente los esfuerzos por reactivarlo.

La contradicción irresoluble que afronta la administración Calderón Sol tiene que ver con cómo se concilian una política económica promotora de un capitalismo neoliberal y una política social que pretende hacer menos lascerantes las condiciones de pobreza y marginalidad de amplios sectores sociales. Hasta ahora, el gobierno ha resuelto esa tcnsión a favor de los grupos empresariales, dejando de lado los desafíos que plantea el bienestar social de los sectores populares, en especial allí donde sus costos van en desmedro -como en los salarios mínimos- de las ganancias empresariales. La tan proclamada "inversión en capital humano" no sólo no ha estado a la altura de las demandas sociales, sino que la misma ha privilegiado aquellas áreas -como sucede con la reforma educativaque capacite a una mano de obra apta para el trabajo en las maquilas. En buena medida, es el interés "globlalizador" del gobierno el que explica el empeño puesto en la reforma educativa, y no tanto un compromiso con el mejoramiento per se de las condiciones de vida de la población. La pésima situación de la salud y la vivienda desmienten brutalmente al mandatario.

Pero, las debilidades del discurso presidencial no se ponen de manifiesto sólo en la incoherencia gubernamental entre el "compromiso" social y la protección a los intereses empresariales, sino también en la grave situación de la seguridad ciudadana y el esfuerzo del gobierno por presentar a las instituciones de seguridad pública como algo ideal. Parece que en la óptica del mandatario, el desempeño del Ministerio de Seguridad y de la Policía Nacional Civil son inmejorables. La última ha combatido el crimen en forma exitosa y si aún tiene algunas limitaciones, la solución es aumentar el número de sus efectivos, hacerlos más eficaces y mejorar su conducta profesional.

La realidad desmiente esta apreciación de Cal-

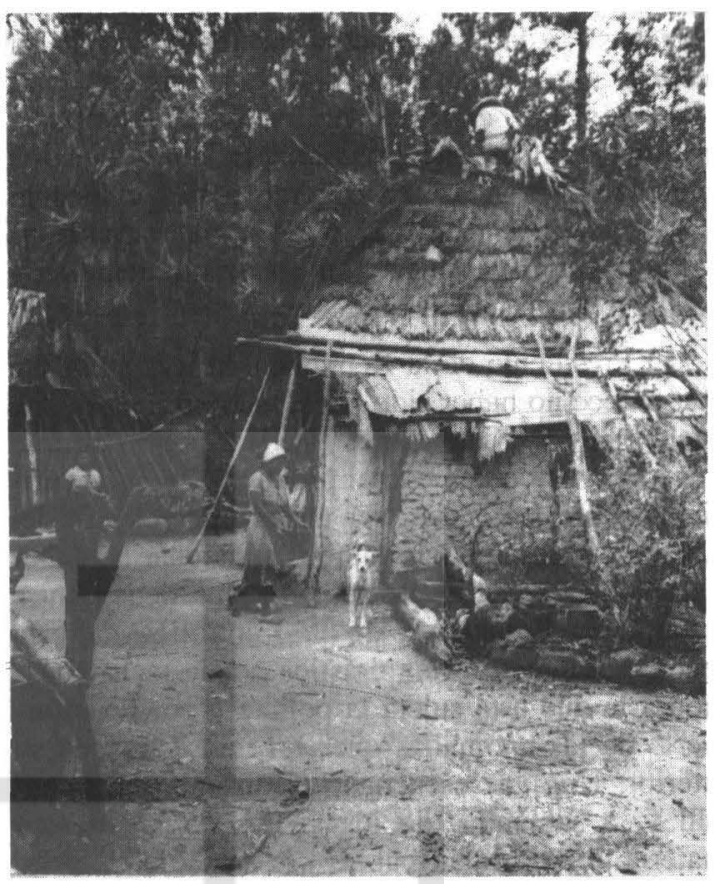

derón Sol, quien debería informarse mejor acerca de los graves problemas que suceden en el interior del organismo policial. En efecto, en las últimas semanas han salido a relucir nuevamente las sospechas de que, en el interior de la Policía Nacional Civil funcionan grupos que no sólo realizan actividades ilegales, sino que operan al margen de sus instancias de control institucional. Esas sospechas han sido reiteradas desde que la nueva policía comenzó su trabajo, ante el desaparecimiento abrupto de la antigua Policía Nacional. Asesinatos, robos, secuestros, violaciones y actividades de narcotráfico han tenido como protagonistas directos a agentes y mandos medios de la Policía Nacional Civil; varios de ellos, incluso, han sido expulsados del cuerpo policial.

Los acontecimientos criminales más recientes, en los que parecen estar involucrados miembros de la Policía Nacional Civil, tienen relación con una serie de asesinatos de presuntos miembros de maras. Desde las altas esferas de gobierno nadie ha dicho nada; el Inspector General de la policía brilla por su ausencia. Es la Procuradora para la Defensa de los Derechos Humanos, Victoria Marina de Avilés, la que se ha atrevido a poner en la mesa de discusión el tema de la responsabilidad policial en esos crímenes. El Ministro de Seguridad Pública, Hugo Barrera, y el Director de la Po- 
licía Nacional Civil, Rodrigo Avila, han pedido "pruebas" a la Procuradora, haciendo uso de un recurso que ya ha demostrado su eficacia para contener las críticas hacia un desempeño institucional bastante cuestionable. $Y$ es que los que piden "pruebas" se refieren a una evidencia que sólo ellos, desde el interior del organismo policial -o una instancia con poder suficiente desde el exterior-, pueden obtener.

El Presidente de la República, al leer su informe, parece no haber sido puesto al corriente de los hechos ni por Avila ni por Barrera. Y ello porque éstos, quizás, creen que el problema no es lo suficientemente serio para ser tratado por el jefe del ejecutivo. Sin embargo, ambos funcionarios deberían tomar en serio el problema que tienen entre manos. El Presidente de la República debería reconvenirlos en forma drástica por la mala dirección a la que está sujeta la policía y por no informarle de las anomalías que se están dando en su interior. Una vez escuchado el discurso presidencial y, a sabiendas de los vacíos del mismo en materia de seguridad pública, la asamblea legislativa debería examinar, en forma detenida, los casos en que está bien fundada la sospecha de participación de agentes de la Policía Nacional Civil en actividades delictivas y pedir al Presidente Calderón Sol que preste atención a la idoneidad de Avila y Barrera para los desafíos que presenta la seguridad ciudadana en la actualidad.

En definitiva, el discurso de Calderón Sol en su tercer año de gobierno puso de manifiesto lo alejada de la realidad que está la visión gubernamental. El Presidente de la República dijo atinadamente que el país requiere, para avanzar hacia el desarrollo social y económico, de un proyecto nacional de largo plazo. Pero ese proyecto nacional no va a funcionar sin una visión de país, es decir, sin un compromiso de los actores económicos, políticos y sociales con los intereses de la nación. ¿Tienen un real interés nacional los grupos financieros? ¿Tienen los políticos una perspectiva de nación? ¿Está forjándose en la sociedad civil un sentido de ciudadanía? Pensar que estas preguntas pueden ser respondidas positivamente es pasarse de optimistas. Para que haya un proyecto de nación tiene que haber un compromiso nacional.

Los empresarios, hasta ahora, no han dado muestras de que su interés sea otro que el de enriquecerse a costa de los bajos salarios, el desempleo o la depredación del medio ambiente. Los políticos no se deciden a abandonar las prácticas tradicionales de la profesión. El gobierno, como queda de manifiesto en el discurso presidencial, no atina a ver por dónde va el país, especialmente porque por miopía o simple desconocimiento no acierta a ver sus problemas fundamentales. Los sectores populares, empeñados como están en sobrevivir, no tienen tiempo de preocuparse por cuáles son los derechos de los demás y los deberes ciudadanos propios. Y así difícilmente se va a poder avanzar como nación.

Los tres años de gobierno de Calderón Sol no han contribuido ni por cerca al establecimiento de las condiciones mínimas para ello. Ha habido, es cierto, un sin fin de Comisiones -aunque formadas por las mismas personas- con los propósitos más elevados y diversos, pero las mismas -salvo la de educación- no han tenido capacidad para incidir en el rumbo real del país. Un gobierno -si ambiciona a orientar como un todo los destinos de una nación- no puede estar sometido a los intereses de uno de los grupos de poder que la constituyen -como lo han denunciado Orlando de Sola y Alfredo Mena Lagos-, por más dinero e influencias que éste sea capaz de movilizar. No puede tampoco evadir o desconocer problemas de alcance nacional. En los dos años que le quedan, Calderón Sol debe mostrar algún empeño en resolver esas dos graves limitaciones que se han hecho patentes tanto en estos tres años de gobierno como en el discurso ofrecido el 1 de junio de 1997.

Luis Armando González 